\title{
PENGARUH SIFAT MACHIAVELLIAN DAN PERKEMBANGAN MORAL TERHADAP DYSFUNCTIONAL BEHAVIOR (STUDI KASUS PADA MAHASISWA S1 AKUNTANSI ANGKATAN 2011 UNIVERSITAS NEGERI YOGYAKARTA)
}

\author{
Oleh : Elsa Vosva Sari \\ Prodi Akuntansi Universitas Negeri Yogyakarta \\ Elsa.vosva.ev@gmail.com \\ Isroah \\ Staf Pengajar Jurusan P. Akuntansi Universitas Negeri Yogyakarta
}

\begin{abstract}
Abstrak
Penelitian ini bertujuan : (1) Mengetahui pengaruh Sifat Machiavellian terhadap Dysfunctional Behavior (Studi Kasus pada Mahasiswa S1 Akuntansi Angkatan 2011 Universitas Negeri Yogyakarta); (2) Mengetahui pengaruh Perkembangan Moral terhadap Dysfunctional Behavior (Studi Kasus pada Mahasiswa S1 Akuntansi Angkatan 2011 Universitas Negeri Yogyakarta); (3) Mengetahui pengaruh Sifat Machiavellian dan Perkembangan Moral terhadap Dysfunctional Behavior (Studi Kasus pada Mahasiswa S1 Akuntansi Angkatan 2011 Universitas Negeri Yogyakarta).

Subjek penelitian ini adalah mahasiswa S1 Akuntansi angkatan 2011 Universitas Negeri Yogyakarta yang diambil sebanyak 72 mahasiswa. Data dikumpulkan melalui kuesioner. Analisis yang digunakan adalah analisis regresi linier sederhana dan analisis regresi linear berganda.

Hasil penelitian ini menunjukkan bahwa (1) Sifat Machiavellian berpengaruh terhadap Dysfunctional Behavior yang ditunjukkan dengan uji ? $_{\text {日国国回 }}$ lebih besar dari $t$ tabel $(2,093>1,667)$. Adapun persamaan regresinya adalah $\mathrm{Y}_{1}=14,433+0,007 \mathrm{X}_{1} ;(2)$ Perkembangan Moral berpengaruh terhadap Dysfunctional Behavior dengan ditunjukkan dengan uji 国国国国 lebih besar dari $t$ tabel $(2,108>1,667)$. Adapun persamaan regresinya adalah $\mathrm{Y}_{1}=15,096-0,009 \mathrm{X}_{2}$; (3) Sifat Machiavellian dan Perkembangan Moral berpengaruh terhadap Dysfunctional Behavior yang ditunjukkan dengan uji ? $_{\text {日国国国 lebih }}$ besar dari 国国国国 $(11,010>3,15)$. Adapun persamaan regresi ganda adalah $\mathrm{Y}=14,845+$ $0,006 \mathrm{X}_{1}-0,008 \mathrm{X}_{2}$.
\end{abstract}

\section{Kata Kunci : Sifat Machiavellian, Perkembangan Moral, Dysfunctional Behavior}

\section{Abstract}

This purpose of this research are : (1) Determine the effect of Machiavellian toward Dysfunctional Behavior (Case Study in the Students Majoring in Accounting 2011 Yogyakarta State University); (2) Determine the effect of Morality Development toward Dysfunctional Behavior (Case Study in the Students Majoring in Accounting 2011 Yogyakarta State University); (3) Determine the effect of Machiavellian and Morality Development toward Dysfunctional Behavior (Case Study in the Students Majoring in Accounting 2011 Yogyakarta State University)

The subjects of this research are 72 students majoring in Accounting 2011 Yogyakarta State University. The data are collected by questionnaire. This research used, simple linear regression analysis and multiple linear regression analysis.

The result of this research shows that (1) Machiavellian has an effect toward Dysfunctional Behavior by showing that $t$ count is bigger than $t$ table (2,093 > 1,667). Whereas the simple linear regression analysis is $Y_{1}=14,433+0,007 X_{1}$; (2) Morality Development has an effect toward Dysfunctional Behavior by showing that $t$ count is bigger 
than t table $(2,108>1,667)$. Whereas the simple linear regression analysis is $Y_{1}=15,096-$ $0,009 \mathrm{X}_{2}$; (3) Machiavellian and Morality Development has an effect toward Dysfunctional Behavior by showing that $F$ count is bigger than $F$ table $(11,010>3.15)$. Whereas the multiple linear regression analysis is $Y=14,845+0,006 X_{1}-0,008 X_{2}$.

Key word: Machiavellian, Morality Development, Dysfunctional Behavior.

\section{A. PENDAHULUAN}

Semakin meningkatnya potensi sumber daya manusia saat ini, mahasiswa merupakan salah satu aset sebagai subjek atau pelaku di dalam pergerakan pembaharuan yang akan menjadi generas-generasi penerus bangsa. Mahasiswa sebagai penerus bangsa seharusnya mampu bertindak untuk membangun bangsa ke arah yang lebih baik. Namun, tindakantindakan mahasiswa sering kali dihadapkan persoalan-persoalan sikap yang dapat melanggar etika. Tindakan mahasiswa merupakan tindakan yang sangat penting guna menunjang karir di masa depan. Untuk memasuki dunia kerja mahasiswa dituntut untuk beretika selayaknya sebagai mahasiswa yang berilmu dan memiliki kemampuan. Mahasiswa pada saatnya akan memasuki dunia kerja. Oleh karena itu, diperlukan stimulasi untuk membuat mahasiswa mulai memikirkan secara serius tentang tindakan dan sikap mahasiswa saat ini, karena bisa jadi akan berkelanjutan saat memasuki dunia kerja.

Perilaku profesional akuntan publik salah satunya diwujudkan dalam bentuk menghindari perilaku disfungsional (dysfunctional behavior). Dysfunctional behavior yang dimaksud merupakan perilaku auditor yang menyimpang dari standar auditing dalam melaksanakan penugasan audit. Perilaku disfungsional yang biasanya dilakukan oleh seorang auditor antara lain melaporkan waktu audit dengan total waktu yang lebih pendek daripada waktu yang sebenarnya (underrepotting of audit time) dan menyelesaikan langkah-langkah audit terlalu dini tanpa melengkapi keseluruhan prosedur (premature sign-off of audit steps without complecton of the prosedure). Kondisi ini membuat masyarakat mempertanyakan keandalan laporan audit yang membentuk opini dilakukan oleh aduitor.

Sikap seorang akuntan publik adalah suatu ekspresi sederhana dari seorang auditor seperti keyakinan dan perasaanya pada saat melaksanakan audit, dimana keyakinan dan perasaan tersebut akan mempengaruhi perilaku dari akuntan publik tersebut. Pada dasarnya sikap yang menentukan perilaku manusia tersebut dibentuk dengan adanya tiga komponen yang saling mempengaruhi yaitu kognitif, negatif dan behavior. Sikap negatif akuntan seperti dilewatinya salah satu prosedur audit karena di anggap low risk. Akuntan tidak begitu mengerti bagaimana melaksanakan prosedur audit tertentu, deadline yang dibebankan oleh klien serta kemalasan dan kebosanan atas pekerjaan audit yang lama dan melelahkan. Dysfunctional merupakan suatu perilaku yang menyimpang dari tujuan organisasi, tetapi keberadaanya bisa ditekan seminimal mungkin.

Seorang akuntan dalam menjalankan profesinya sebagai pemeriksa (auditor), diatur berdasarkan suatu kode etik profesi. Di Indonesia dikenal dengan Kode Etik Akuntansi Indonesia, dalam kode etik IAI terdiri atas empat bagian yang disusun berdasarkan struktur atau jenajng (hierarchy), yaitu prinSip etika, aturan etika, interpretasi aturan etika dan tanya jawab etika (Sukrisno Agoes, 2009).

Profesi akuntan publik merupakan salah satu kunci di masa era globalisasi, oleh karena itu dibutuhkan kesiapan profesionalisme dari setiap anggota profesi yang meliputi keahlian, pengetahuan dan karakter. Karakter merupakan personality kepribadian seorang profesional yang diantarnta diwujudkan dalam perilaku etis dan tindakan etis (Chismastuti 
dan Purnamasari, 2004). Karakter moral berkenaan dengan ipersonality seperti kekuatan ego, kegigihan, kekerasan hati, pemikiran dan kekuatan akan pendirian serta keberanian yang berguna untuk tindakan yang benar. Seorang individu yang memiliki kemampuan dalam menetukan apa yang secara moral baik atau buruk dan benar atau salah akan gagal atau salah dalam bertindak secara moral sebagi hasil dari kegagalan dalam mengidentifikasi persoalan-persoalan moral (Walker, 2007).

Richmon (2001) meneliti hubungan suatu sifat yang membentuk suatu tipe kepribadian yaitu sifat Machivellian yang diukur dengan instrumen Mach IV Score dengan kecenderungan perilaku akuntan dalam menghadapi dilema-dilema etika. Sifat Machiavellian berpengaruh pada kecenderungan akuntan untuk menerima perilakuperilaku dilematis yang berhubungan dengan etika profesinya. Hal ini menunjukkan bahwa semakin tinggi kecenderungan sifat Machiavellian seorang akuntan maka semakin tinggi pula kecenderungan untuk menerima perilaku atau tindakan-tindakan yang dilemas secara etis. Sifat machiavellian mempunyai kecenderungan untuk mementingkan kepentingan sendiri, manipulatif dan agresif. Sifat machivellian merupakan sifat yang kemungkinan ada dalam persepsi segala profesi bisnis, terutama bagi profesi akuntan dan auditor. Seseorang yang berprofesi sebagai akuntan atau auditor dituntut untuk mempunyai tanggung jawab etis yang lebih, dibandingkan dengan profesi lainnya. Sebagai auditor, profesi yang dijalankan sangat bergantung pada kepercayaan masyarakat sebagai pengguna jasa profesi.

Sifat Machiavellian dan perkembangan moral ini juga diindikasikan dapat berpengaruh secara langsung terhadap perilaku disfungsional (dysfunctional behavior). Individu dengan sifat maciavellian tinggi cenderung memanfaatkan situasi untuk mendapatkan keuntungan pribadi dan lebih memiliki keinginan untuk tidak taat pada aturan serta cenderung memiliki perilaku disfungsional (dysfunctional behavior) (Gosh dan Crain, 1996). Sedangkan perkembangan moral yang dimiliki setiap individu juga akan menggambarkan seberapa jauh individu tersebut memiliki perilaku disfungsional.

Sifat machiavellian dan perkembangan moral yang dimiliki oleh setiap mahasiswa akuntansi atau calon auditor akan berpengaruh terhadap perilaku mereka pada saat memasuki dunia kerja. Perilaku mahasiswa dimana mereka akan memasuki kerja, sangat penting diperhatikan untuk menghindari perilaku-perilaku yang tidak semestinya atau perilaku disfungsional. Dalam penelitian ini, peneliti akan memberikan kuesioner dimana mahasiswa S1 Universitas Negeri Yogyakarta diperlakukan sebagai akuntan atau auditor, untuk mengetahui seberapa besar pengaruh sifat machiavellian dan perkembangan moral terhadap dysfunctional behavior mahasiswa miliki. Atas dasar pemikiran dan uraian tersebut maka penulis mengadakan suatu penelitian dengan judul "Pengaruh Sifat Machiavellian dan Perkembangan Moral terhadap Dysfunctional Behavior (Studi Kasus pada Mahasiswa S1 Akuntansi Angkatan 2011 Universitas Negeri Yogyakarta )”.

\section{B. METODE PENELITIAN}

\section{Tempat danWaktu Penelitian}

Penelitian ini adalah studi kasus pada Mahasiswa S1 Akuntansi Angkatan 2011 Universitas Negeri Yogyakarta. Yang beralamat di J1. Colombo No.1 Yogyakarta 55281. Waktu penelitian di laksanakan pada bulan Oktober-November 2014.

\section{JenisPenelitian}

Jenis penelitian ini adalah penelitian dengan metode kausal komparatif. Metode kausal komparatif (causal comparative research) yang disebut juga penelitian ex post 
facto adalah penelitian empiris yang sistematis di mana peneliti tidak pengendalikan variabel bebas secara langsung karena keberadaaan dari variabel tersebut telah terjadi atau karena variabel tersebut pada dasarnya tidak dapat dimanipulasi.

\section{Subjek dan Objek Penelitian}

Subjek penelitian ini adalah Mahasiswa S1 Akuntansi Angkatan 2011 Universitas Negeri Yogyakarta. Objek pada penelitian ini adalah hasil kuesioner yang telah diisi oleh Mahasiswa S1 Akuntansi Angkatan 2011 Universitas Negeri Yogyakarta, yang berhubungan dengan penelitian ini.

\section{Definisi Operasional Variabel Penelitian}

\section{a. Variabel Dependen (Y)}

Variabel independennya adalah Dysfunctional Behavior. Perilaku Disfungsional merupakan perilaku individu yang memiliki konflik dasar dengan tujuan organisasi (Hansen dan Mowen, 2005). Perilaku disfungsional merupakan reaksi terhadap lingkungan, perilaku ini bisa mempunyai pengaruh secara langsung dan tidak langsung terhadap mutu audit. Perilaku disfungsional terjadi pada situasi ketika individu merasa dirinya kurang mampu mencapai hasil yang diharapkan melalui usahanya sendiri.

Adapun indikator dari variabel tersebut, adalah :

a. Premature Sign-Off

b. Underreporting of Time

\section{b. Variabel Independen}

a) Sifat Machiavellian $\left(\mathrm{X}_{1}\right)$

Christie dan Geis (1970) dalam penelitiannya mendeskripsikan kepribadian Machiavellian sebagai suatu kepribadian antisosial, yang tidak memperhatikan moralitas konvensional dan mempunyai komitmen ideologis yang rendah. Disini, seorang Machiavellian mempunyai kecenderungan untuk mementingkan kepentingan sendiri, manipulatif dan agresif. Menurut Chrismastuti dan Purnamasari (2004), Skala Machiavellian (Skala Mach IV) merupakan instrumen yang tepat untuk mengukur kecenderungan sikap etis Akuntan (Auditor). Akuntan (Auditor) dengan skala Machiavellian tinggi cenderung menerima sikap-sikap yang secara etis diragukan.

Adapun indikator dari variabel tersebut, adalah :

a) Afeksi

b) Komitmen ideologis rendah

c) Ego

d) Manipulatif

e) Agresif

b) Perkembangan Moral $\left(\mathrm{X}_{2}\right)$

Perkembangan moral didefinisikan sebagai pertimbangan - pertimbangan untuk mengantisipasi dilema etis (Rest et al dalam Sukrisno Agoes (2009). Dalam praktiknya, model Kohlberg tidak selalu menunjukkan adanya hubungan antara pertambahan usia dengan peningkatan kessadaran moral. Dewasa ini, banyak fakta baik di Indonesia maupun dibelahan dunia lain dimana pertambahan usia seseorang tidak serta merta diikuti oleh pertumbuhan tingkat kesadaran moralnya.

Adapun indikator dari variabel tersebut, adalah :

a. Ketaatan

b. Individualisme 

c. Norma Interpersonal
d. Moralitas Sistem Sosial
e. Orientasi Kontak Sosial
f. Prinsip Etika

\section{Populasi dan Sampel}

Populasi pada penelitian ini adalah Mahasiswa S1 Akuntansi Angkatan 2011 di Universitas Negeri Yogyakarta. Teknik pengambilan sampel dalam penelitian ini adalah purposive sampling yaitu pengambilan sampel yang diambil secara sengaja oleh peneliti. Jadi sampel tidak secara acak, tetapi ditentukan oleh peneliti.

\section{Teknik Pengumpulan Data}

Teknik pengambilan data pada penelitian ini adalah teknik kuesioner dalam menggunakan data yang dibutuhkan. Kuesioner nantinya akan di rancang sedemikan rupa yang sesuai dengan penelitian ini yaitu Pengaruh Sifat Machiavellian dan Perkembangan Moral terhadap Dysfunctional Behavior, dengan setiap item diberikan nilai atau bobot guna mengihitung hasilnya. Kuesioner ini nantinya di sebarkan pada Mahasiswa S1 Akuntansi Angkatan 2011 Universitas Negeri Yogyakarta.

\section{Instrumen Penelitian}

a. Kisi - Kisi Intrumen

Instrumen penelitian ini merupakan alat yang dipakai untuk pengambilan data yang diperlukan dalam penelitian tersebut. Instrumen dalam penelitian ini berupa angket (kuesioner) yang berisi pertanyaan yang perlu dijawab dan diisi oleh responden. Angket tersebut berisi pertanyaan tentang sikap calon auditor untuk mengetahui seberapa besar sikap calon auditor.

b. Uji Coba Kuesioner

Kuesioner penelitian harus diuji terlebih dahulu sebelum digunakan dalam penelitian yang sesungguhnya. Tujuan dilakukan uji coba instrumen adalah untuk mengetahui apakah instrumen yang digunakan benar-benar merupakan instrumen yang baik. Uji coba instrumen penelitian dilakukan dengan menggunakan Uji Validitas dan Uji Reliabilitas. Uji Validitas dan Uji Reliabilitas dalam penelitian ini dilakukan pada sampel berjumlah 30 Mahasiswa S1 Akuntansi Angkatan 2010 Universitas Negeri Yogyakarta.

\section{Teknik Analisis Data}

a. Analisis Deskriptif Presentatif

Metode ini digunakan untuk mengkaji variabel yang ada pada penelitian yaitu Sifat Machiavellian $\left(\mathrm{X}_{1}\right)$, Perkembangan Moral $\left(\mathrm{X}_{2}\right)$ dan Dysfunctional Behaviorh (Y) studi kasus pada Mahasiswa S1 Angkatan 2011 Universitas Negeri Yogyakarta. Deskriptif persentase ini diolah dengan cara frekuensi dibagi dengan jumlah responden dikali 100 persen, seperti dikemukakan Sudjana (2001: 129) adalah sebagai berikut:

? $=\frac{\text { ? }}{\text { ? }}$ ? $100 \%$

b. Analisis Regresi Linier Sederhana 
Analisis regresi linier sederhana didasarkan pada hubungan fungsional ataupun kasual suatu variabel independen dengan satu variabel dependen. Dalam menghitung analisis regresi linier sederhana dibantu dengan program SPSS.

c. Analisis Regresi Linier Berganda

Analisis regresi ganda adalah regresi yang menggunakan lebih dari satu variabel independen guna menduga variabel dependen. Dalam menghitung analisis regresi linier berganda dibantu dengan program SPSS.

d. Uji Asumsi Klasik

1) Uji Multikolinieritas

Uji asumsi klasik jenis ini diterapkan untuk analisis regresi linear berganda yang terdiri atas dua atau lebih variabel bebas atau variabel independen yang diukur tingkat asosiasi (keeratan) hubungan atau pengaruh antar variabel bebas. Untuk menentukan ada tidaknya multikolinearitas dapat dilakukan dengan menghitung nilai tolerance (a) atau dengan menghitung nilai variance inflation factor (VIF).Untuk mengetahui ada tidaknya multikolinier menurut perhitungan yang dilakukan dengan program SPSS.

2) Uji Heterokedastisitas

Dalam persamaan regresi berganda perlu juga dilakukan pengujian heterokedastisitas. Pengujian ini mengenai sama atau tidaknya varians dari residual dari obeservasi yang satu dengan observasi yang lain. Jika residualnya mempunyai varian yang sama, disebut terjadi hemoskedastisitas dan jika variansnya tidak sama atau berbeda disebut terjadi heteroskedastisitas.

Cara untuk mengetahui ada atau tidaknya heterokedastisitas adalah dengan program SPSS, yaitu grafik scatterplot antar Z prediction (ZPRED) yang merupakan variabel bebas (sumbu $\mathrm{X}=\mathrm{Y}$ hasil prediksi) dan bila residualnya (SRESID) merupakan variabel terikat $(\mathrm{Y}=\mathrm{Y}$ presiksi $-\mathrm{Y}$ riil $)$.

e. Uji Hipotesis

1) Uji t

Uji t digunakan yntuk menguji pengaruh masing-masing variabel bebas yaitu Sifat Machiavellian dan Perkembangan Moral terhadap Dysfunctional Behavior. Uji hipotesis ini dengan uji $\mathrm{t}$ dengan mencari t hitung dan membandingkan dengan $t$ tabel. Nilai $t$ hitung dapat diketahui dari hasil perhitungan analisis regresi berganda dengan bantuan program SPSS.

Kaidah pengujian :

Ho ditolak jika thitung < dari $t$ tabel.

Ho diterima jika $t$ hitung $>$ dari $t$ tabel.

2) Uji F

Uji $\mathrm{F}$ dikenal dengan overall significance test. Tujuan dati uji $\mathrm{F}$ adalah untuk menguji signifikansi pengaruh variabel bebas yakni Sifat Machiavellian dan Perkembangan Moral terhadap variabel terikat yakni Dysfunctional Behavior secara bersama-sama. Pengujian secara bersama-sama menggunakan distribusi $\mathrm{F}$ yaitu membandingkan antara $\mathrm{F}$ hitung dan $\mathrm{F}$ tabel. Kriteria penerimaan dan penolakan hipotesis adalah :

Jika F hitung < F-tabel, maka Ho ditolak.

Jika F hitung > F-tabel, maka Ho diterima.

Berdasarkan dasar signifikan, kriterianya adalah :

Jika nilai signifikansi > 0, 05 maka signifikan.

Jika nilai signifikansi $<0,05$ maka tidak signifikan.

\section{HASIL PENELITIAN DAN PEMBAHASAN}

\section{Hasil Penelitian}


a. Data Umum

Penelitian ini dilakukan dengan menyebarkan kuesioner kepada Mahasiswa Akuntansi S1 Angkatan 2011 Universitas Negeri Yogyakarta. Hal ini dilakukan untuk memperoleh data yang nantinya diketahui pengaruh dari Sifat Machiavellian dan Perkembangan Moral terhadap Dysfunctional Behavior.

Responden terdiri dari 72 mahasiswa Akuntansi S1 Angkatan 2011 Universitas Negeri Yogyakarta. Penyebaran kuesioner ini dilakukan dengan syarat mahasiswa sudah menempuh mata kuliah Auidit 1 dan Audit 2, karena mata kuliah tersebut telah memberikan ilmu yang berkaitan dengan penelitian ini.

Kuesioner tersebut di bagikan secara langsung kepada mahasiswa Akuntansi. Kuesioner yang disebarkan terdiri dari Sifat Machiavellian yang disajikan sebanyak 15 item atau butir pertanyaan, Perkembangan moral sebanyak 18 item atau butir pertanyaan dan Dysfunctional Behavior sebanyak 6 item atau butir pertanyaan. Pertanyaan dari Sifat Machiavellian erdiri dari afeksi, komitmen ideologis rendah, ego, manipulatif dan agresif. Perkembangan Moral terdiri dari pertanyaan-pertanyaan tentang ketaatan, individualis, norma interpersonal, moralitas sistem sosial, orientasi kontrak social dan prinsip etika. Pertanyaan untuk Dysfunctional Behavior adalah premature sign-off dan underreporting of time.

b. Data Khusus

1) Uji Validitas

Perhitungan validitas instrumen didasarkan perbandingan antara $r$ hitung dan $r$ tabel. Apabila $r$ hitung lebih besar dari $r$ tabel pada signifikan 5\% maka data bisa dikatakan valid. Sebaliknya, jika $r$ hitung lebih kecil dari $r$ tabel maka data tidak valid. Pengujian validitas dengan bantuan SPSS 16.0 menghasilkan data sebagai berikut:

\section{Tabel 1. Hasil Pengujian Validitas}

\begin{tabular}{|l|c|c|}
\hline \multicolumn{1}{|c|}{$\begin{array}{c}\text { Item } \\
\text { pertanyaan }\end{array}$} & $\begin{array}{c}\text { Jumla } \\
\text { h Item }\end{array}$ & Hasil \\
\hline $\begin{array}{l}\text { Dysfuntional } \\
\text { Behavior }\end{array}$ & 6 & $\begin{array}{c}\text { Vali } \\
\mathrm{d}\end{array}$ \\
\hline $\begin{array}{l}\text { Sifat } \\
\text { Machiavellian }\end{array}$ & 15 & $\begin{array}{c}\text { Vali } \\
\mathrm{d}\end{array}$ \\
\hline $\begin{array}{l}\text { Perkembangan } \\
\text { Moral }\end{array}$ & 18 & $\begin{array}{c}\text { Vali } \\
\mathrm{d}\end{array}$ \\
\hline
\end{tabular}

Sumber : data primer yang diolah

2) Uji Reabilitas

Suatu kuesioner dikatakan reliabel atau handal jika jawaban seseorang terhadap pernyataan adalah konsisten atau stabil dari waktu ke waktu. Uji reliabilitas menggunakan uji Cronbach's Alpha, data dikatakan reliabel apabila nilai Alpha lebih dari 0,6, dan apabila nilai Alpha kurang dari 0,6 maka data dikatakan tidak reliabel. Pengujian reliabilitas menggunakan bantuan SPSS 16.0 dan hasilnya adalah :

\section{Tabel 2. Hasil Pengujian Reabilitas}

\begin{tabular}{|l|c|c|}
\hline Item pertanyaan & $\begin{array}{c}\text { Koefisie } \\
\mathrm{n} \text { Alpha }\end{array}$ & hasil \\
\hline $\begin{array}{l}\text { Dysfuntional } \\
\text { Behavior }\end{array}$ & 0,739 & $\begin{array}{c}\text { Reliabe } \\
1\end{array}$ \\
\hline
\end{tabular}




\begin{tabular}{|l|c|c|}
\hline $\begin{array}{l}\text { Sifat } \\
\text { Machiavellian }\end{array}$ & 0,688 & $\begin{array}{c}\text { Reliabe } \\
1\end{array}$ \\
\hline $\begin{array}{l}\text { Perkembangan } \\
\text { Moral }\end{array}$ & 0,652 & $\begin{array}{c}\text { Reliabe } \\
1\end{array}$ \\
\hline
\end{tabular}

Sumber : data primer yang diolah

\section{Analisis Data dan Pembahasan}

\section{a. Teknik Analisis Data}

1) Analisis Deskriptif Presentatif

a) Dysfuntional Behavior

Berikut adalah data yang diperoleh dari hasil penelitian berupa hasil kuesioner yang dilakukan pada 72 Mahasiswa Akuntansi S1 Angkatan 2011 Universitas Negeri Yogyakarta. Dari 72 kuesioner yang telah dibagikan, keseluruhan dapat diisi sesuai dengan kriteria yang telah ditetapkan oleh peneliti.

Tabel 3. Data Kuesioner Dysfunctional Behavior

\begin{tabular}{|c|c|}
\hline $\begin{array}{c}\text { Dysfunctiona } \\
\text { l Behavior }\end{array}$ & $\begin{array}{c}\text { Jumlah } \\
\text { Mahasisw } \\
\text { a }\end{array}$ \\
\hline $5-7$ & 1 \\
\hline $8-10$ & 2 \\
\hline $11-13$ & 11 \\
\hline $14-16$ & 51 \\
\hline $17-19$ & 5 \\
\hline $20-22$ & 1 \\
\hline $23-25$ & 1 \\
\hline Jumlah & $\mathbf{7 2}$ \\
\hline
\end{tabular}

Sumber : data primer yang diolah

Jumlah score ideal (kriterium) untuk seluruh item $=4 \times 6 \times 72=1.728$ (seandainya jawaban semua SS). Berdasarkan data pada lampiran, score yang diperoleh dari hasil penelitian adalah 1.057. Berdasarkan data tersebut 
dysfunctional behavior pada studi kasus mahasiswa akuntansi S1 angkatan 2011

Universitas Negeri Yogyakarta dapat diketahui melalui perhitungan berikut :

? $=\frac{\text { ? }}{\text { ? }}$ ? $100 \%$

? $=\frac{1057}{1728} \times 100 \%=61,2 \%$

Berdasarkan perhitungan Dysfunctional Behavior pada studi kasus mahasiswa akuntansi S1 angkatan 2011 Universitas Negeri Yogyakarta di atas diperoleh bahwa Dysfunctional Behavior sebesar 61,2\% dari total $100 \%$ yang diharapkan. Secara kontinum dapat digambarkan seperti berikut :

\begin{tabular}{|c|c|c|c|c|}
\hline SKB & $\mathrm{K}$ & C & B & SB \\
\hline & & $B$ & & \\
\hline & 2 & 40 & & 80 \\
\hline
\end{tabular}

Berdasarkan perhitungan data dan gambar kontinum di atas, yang diperoleh dari 72 responden maka rata-rata $61,2 \%$ terletak pada kategori baik (B), artinya Dysfunctional Behavior pada studi kasus mahasiswa akuntansi S1 angkatan 2011 Universitas Negeri Yogyakarta adalah baik.

b) Sifat Machiavellian

Berikut adalah data yang diperoleh dari hasil penelitian berupa hasil kuesioner yang dilakukan pada 72 Mahasiswa Akuntansi S1 Angkatan 2011 Universitas Negeri Yogyakarta dapat diihat sebagai berikut :

Tabel 4. Data Kuesioner Sifat Machiavellian

\begin{tabular}{|c|c|}
\hline $\begin{array}{c}\text { Sifat } \\
\text { Machiavellia } \\
\boldsymbol{n}\end{array}$ & $\begin{array}{c}\text { Jumlah } \\
\text { Mahasisw } \\
\mathbf{a}\end{array}$ \\
\hline $22-25$ & 1 \\
\hline $26-29$ & 0 \\
\hline $30-33$ & 8 \\
\hline $34-37$ & 38 \\
\hline $38-40$ & 16 \\
\hline $41-44$ & 6 \\
\hline $45-48$ & 3 \\
\hline Jumlah & $\mathbf{7 2}$ \\
\hline
\end{tabular}

Sumber: data primer yang diolah

Jumlah score ideal (kriterium) untuk seluruh item $=4 \times 15 \times 72=4.320$ (seandainya jawaban semua SS). Berdasarkan data pada lampiran, score yang diperoleh dari hasil penelitian adalah 2.622. Berdasarkan data tersebut Sifat Machiavellian pada studi kasus Mahasiswa Akuntansi S1 Angkatan 2011 Universitas Negeri Yogyakarta dapat diketahui melalui perhitungan berikut :

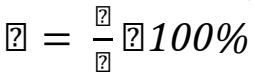

$$
\begin{aligned}
& \text { ? }=\frac{2.622}{4.320} \times 100 \%=60,7 \%
\end{aligned}
$$

Berdasarkan perhitungan Sifat Machiavellian pada studi kasus Mahasiswa Akuntansi S1 Angkatan 2011 Universitas Negeri Yogyakarta di atas diperoleh bahwa Sifat Machiavellian sebesar $60,7 \%$ dari total $100 \%$ yang diharapkan. Secara kontinum dapat digambarkan seperti berikut : 


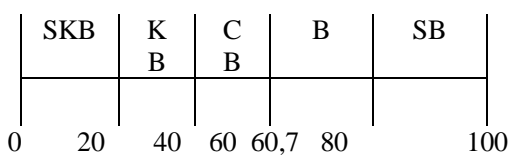

Berdasarkan perhitungan data dan gambar kontinum di atas, yang diperoleh dari 72 responden maka rata-rata 60,7\% terletak pada kategori baik (B), artinya Sifat Machiavellia pada studi kasus Mahasiswa Akuntansi S1 Angkatan 2011 Universitas Negeri Yogyakarta adalah baik.

c) Perkembangan Moral

Berikut adalah data yang diperoleh dari hasil penelitian berupa hasil kuesioner yang dilakukan pada 72 Mahasiswa Akuntansi S1 Angkatan 2011 Universitas Negeri Yogyakarta dapat diihat sebagai berikut :

Tabel 5. Data Kuesioner Perkembangan Moral

\begin{tabular}{|c|c|}
\hline $\begin{array}{c}\text { Perkembanga } \\
\text { n Moral }\end{array}$ & $\begin{array}{c}\text { Jumlah } \\
\text { Mahasisw } \\
\text { a }\end{array}$ \\
\hline $33-36$ & 1 \\
\hline $37-40$ & 1 \\
\hline $41-44$ & 7 \\
\hline $45-48$ & 34 \\
\hline $49-52$ & 25 \\
\hline $53-56$ & 2 \\
\hline $57-60$ & 2 \\
\hline Jumlah & $\mathbf{7 2}$ \\
\hline
\end{tabular}

Sumber: data primer yang diolah

Jumlah score ideal (kriterium) untuk seluruh item $=4$ × 18 × $72=5.184$ (seandainya jawaban semua SS). Berdasarkan hasil data yang terlampir, score yang diperoleh dari hasil penelitian adalah 3.456. Berdasarkan data tersebut Perkembangan Moral pada studi kasus Mahasiswa Akuntansi S1 Angkatan 2011

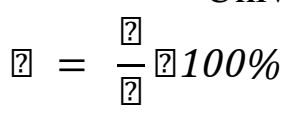

Universitas Negeri Yogyakarta dapat diketahui melalui perhitungan berikut :

$$
\text { ? }=\frac{3.456}{5.184} \times 100 \%=66,7 \%
$$

Berdasarkan perhitungan Perkembangan Moral pada studi kasus Mahasiswa Akuntansi S1 Angkatan 2011 Universitas Negeri Yogyakarta di atas diperoleh bahwa perkembangan moral sebesar $66,7 \%$ dari total $100 \%$ yang diharapkan. Secara kontinum dapat digambarkan seperti berikut :

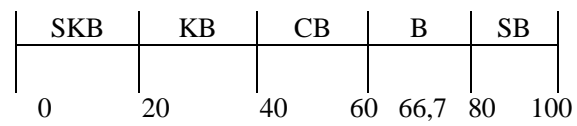

Berdasarkan perhitungan data dan gambar kontinum di atas, yang diperoleh dari 72 responden maka rata-rata 66,7\% terletak pada kategori baik (B). Artinya Perkembangan Moral pada studi kasus Mahasiswa Akuntansi S1 Angkatan 2011 Universitas Negeri Yogyakarta adalah baik.

2) Analisis Regresi Sederhana

a) Sifat Machiavellian terhadap Dysfunctional Behavior 
Berdasarkan data pada tabel coefficients yang terlampir, diperoleh nilai $a$ sebesar 14,433 sedangkan nilai $b$ sebesar 0,007 , secara lebih rinci dapat dilihat pada lampiran. Dari nilai $a$ dan $b$ yang didapatkan selanjutnya dapat diketahui persamaan linier sederhana pengaruh Sifat Machiavellian terhadap Dysfunctional Behavior sebagai berikut :

$\mathrm{Y}_{1}=14,433+0,007 \mathrm{X}_{1}$

Persamaan di atas menunjukkan bahwa nilai $a$ dan $b$ positif. Artinya ketika variabel $\mathrm{X}_{1}$ (Sifat Machiavellian) dinaikkan maka nilai Y (Dysfunctioanel Behavior) juga naik mengikuti perubahan variabel $\mathrm{X}_{1}$.

b) Perkembangan Moral terhadap Dysfunctional Behavior.

Berdasarkan perhitungan yang terlampir, diperoleh nilai $a$ sebesar 15,096 sedangkan nilai $b$ sebesar - 0,009, secara lebih rinci dapat dilihat pada perhitungan analisis regresi linier sederhana yang terlampir. Dari nilai $a$ dan $b$ yang didapatkan selanjutnya dapat diketahui persamaan linier sederhana pengaruh perkembangan moral terhadap dysfunctional behavior sebagai berikut :

$\mathrm{Y}=15,096-0,009 \mathrm{X}$

Persamaan di atas menunjukkan bahwa nilai $a$ positif dan $b$ negatif. Artinya ketika variabel $\mathrm{X}_{1}$ (Perkembangan Moral ) dinaikkan maka nilai $\mathrm{Y}$ (Dysfunctioanel Behavior) akan turun mengikuti perubahan variabel $\mathrm{X}_{2}$.

c) Sifat Machiavellian dan Perkembangan Moral terhadap Dysfunctional Behavior

Berdasarkan data yang terlampir, diperoleh nilai ${ }_{1}$ sebesar 0,006, ? ${ }_{2}$ sebesar $-0,008$ dan ? sebesar 14,845. Untuk lebih terinci dapat dilihat pada perhitungan di lampiran untuk perolehan data tersebut. Dari nilai $b_{1}, b_{2}$, dan a yang didapatkan selanjutnya dapat diketahui persamaan garis regresi pengaruh Sifat Machiavellian dan Perkembangan Moral terhadap Dysfunctional Behavior sebagai berikut :

$\mathrm{Y}=14,845+0,006 \mathrm{X}_{1}-0,008 \mathrm{X}_{2}$

Persamaan di atas menunjukkan bahwa nilai $\mathrm{b}_{1}$ dan a positif, sedangkan $\mathrm{b}_{2}$ negatif. Dalam persamaan di atas, nilai a adalah Dysfunctional Behavior tanpa pengaruh Sifat Machiavellian dan Perkembangan Moral .Konstanta $\mathrm{b}_{1} \mathrm{dan}_{\mathrm{b}_{2}}$ adalah besar perubahan $\mathrm{X}_{1}$ dan $\mathrm{X}_{2}$ terhadap $\mathrm{Y}$.

3) Uji Asumsi Klasik

a) Uji Multikolinieritas

Berikut adalah tabel hasil uji multikolinearitas secara rinci dapat dilihat pada tabel coefficients terlampir yang dapat menggambarkan multikolinier.

Tabel 6. Hasil Uji Multikolinearitas

\begin{tabular}{|c|c|c|c|}
\hline \multirow{2}{*}{$\begin{array}{l}\mathrm{N} \\
\mathrm{o}\end{array}$} & \multirow{2}{*}{ Variabel } & \multicolumn{2}{|c|}{$\begin{array}{c}\text { Collinearity } \\
\text { Statistics }\end{array}$} \\
\cline { 3 - 4 } & & $\begin{array}{c}\text { Toleranc } \\
e\end{array}$ & VIF \\
\hline 1 & $\begin{array}{c}\text { Sifat } \\
\text { Machiavellian }\end{array}$ & 0,998 & $\begin{array}{c}1,00 \\
2\end{array}$ \\
\hline 2 & $\begin{array}{c}\text { Perkembanga } \\
\text { n Moral }\end{array}$ & 0,998 & $\begin{array}{c}1,00 \\
2\end{array}$ \\
\hline
\end{tabular}

Sumber: data primer yang diolah

Pada tabel hasil uji multikolinearitas di atas, pada kolom Tolerance nilai dari Sifat Machiavellian adalah 0,998 yang artinya Tolerance $>0,10$ dan Perkembangan Moral adalah 0,998 yang artinya nilai Tolerance $>0,10$. Pada kolom VIF (Value Inflantion Factor) nilai dari Sifat Machiavellian adalah 1,002 
yang artinya VIF $<10$ dan Perkembangan Moral adalah 1,002 yang artinya VIF $<$ 10. Dengan demikian dapat ditarik kesimpulan bahwa uji multikolinearitas yang telah dihitung dengan menggunakan bantuan SPSS untuk menguji pengaruh sifat machiavellian dan perkembangan terhadap dysfunctinal behavior adalah tidak terjadi multikoliearitas, maka uji multikolinearitas terpenuhi, yaitu nilai Tolerance $>0,10$ dan $\mathrm{VIF}<10$.

b) Uji Heterokedastisitas

Untuk mendeteksi ada atau tidaknya heterokedastisitas yaitu dengan melihat grafik Plot antara nilai prediksi variabel terikat (dependen) yaitu ZPRED dengan residualnya SRESID. Deteksi ada atau tidaknya pola tertentu pada grafik scatterplot antara SRESID dan ZPRED dimana sumbu Y adalah Y yang telah diprediksi dan sumbu $\mathrm{X}$ adalah residualnya. Dasar analisis untuk melihat grafik scatterplot adalah :

(1) Jika ada pola tertentu, seperti titik-titik yang membentuk pola tertentu yang teratur (bergelombang, melebar kemudian menyempit), maka diindikasikan telah terjadi heterodekastisitas.

(2) Jika tidak ada pola yang jelas, serta titik-titik yang menyebar di atas dan di bawah angka 0 pada sumbu $\mathrm{Y}$, maka tidak terjadi heterokedastisitas.

Berikut adalah grafik scatterplot pada output data yang menjelaskan tentang hubungan pengaruh Sifat Machiavellian dan Perkembangan Moral terhadap Dysfunctional Behavior :

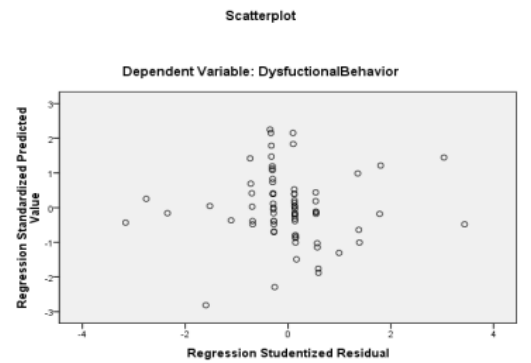

\section{Gambar 2. Grafik Scatterplot}

Pada gambar di atas dapat diketahui bahwa tidak terjadi heterokedastisitas, sebab tidak ada pola yang jelas serta titik-titik menyebar di atas dan di bawah angka 0 pada sumbu Y, sehingga dapat dikatakan bahwa uji heterokedastisitas terpenuhi..

4) Uji Hipotesis

a) Hipotesis pertama

Pengujian hipotesis yang pertama adalah "Sifat Machiavellian berpengaruh terhadap Dysfunctional Behavior (studi kasus pada Mahasiswa S1 Akuntansi Angkatan 2011 Universitas Negeri Yogyakarta)". Pengujian dilakukan dengan bantuan SPSS16.0, dan diperoleh nilai $t$ hitung sebesar 2.093 sedangkan $t$ tabel dengan $\mathrm{n}=70$ dan $\alpha=0,05$ diperoleh nilai sebesar 1,667.

Hasil tersebut menunjukkan bahwa $t$ hitung lebih besar dari $t$ tabel (2.093 > 1,667) sehingga hipotesis dapat diterima. Hasil dari perhitungan tersebut menunjukkan bahwa Sifat Machiavellian berpengaruh terhadap Dysfunctiobal Behavior studi kasus pada Mahasiswa S1 Akuntansi Angkatan 2011 Universitas Negeri Yogyakarta.

b) Hipotesis kedua

Pengujian hipotesis yang kedua adalah "Perkembangan Moral berpengaruh terhadap Dysfunctional Behavior (studi kasus pada Mahasiswa S1 Akuntansi Angkatan 2011 Universitas Negeri Yogyakarta)". Pengujian dilakukan dengan 
bantuan SPSS16.0, dan diperoleh nilai $t$ hitung sebesar 2,108 sedangkan $t$ tabel dengan $\mathrm{n}=70$ dan $\alpha=0,05$ diperoleh nilai sebesar 1,667.

Hasil tersebut menunjukkan bahwa $t$ hitung lebih besar dari $t$ tabel $(2,108>$ 1,667) sehingga hipotesis dapat diterima.Hasildari perhitungan tersebut menunjukkan bahwa Perkembangan Moral berpengaruh terhadap Dysfunctional Behavior studi kasus pada Mahasiswa S1 Akuntansi Angkatan 2011 Universitas Negeri Yogyakarta.

c) Hipotesis ketiga

Pengujian hipotesis yang ketiga adalah "Sifat Machiavellian dan Perkembangan Moral berpengaruh secara bersama-sama terhadap Dysfunctional Behavior (studi kasus pada Mahasiswa S1 Akuntansi Angkatan 2011 Universitas Negeri Yogyakarta)".

Hal ini dibuktikan dengan $\mathrm{R}$ hitung adalah 0,517 dan hasil $\mathrm{F}$ hitung adalah 11.010. Bila taraf kesalahan 5\%, maka diperoleh harga $F$ tabel adalah 3,15, jadi $\mathrm{F}$ hitung lebih besar dari $\mathrm{F}$ tabel $(11,010>3,15)$. Jadi terdapat hubungan antara Sifat Machiavellian dan Perkembangan Moral secara bersama-sama terhadap Dysfunctional Behavior studi kasus pada Mahasiswa S1 Akuntansi Angkatan 2011 Universitas Negeri Yogyakarta.

\section{Pembahasan}

Berdasarkan hasil analisis yang sudah dilakukan, maka pembahasan tentang hasil penelitian adalah sebagai berikut:

1. Pengaruh Sifat Machiavellian terhadap Dysfunctional Behavior pada Mahasiswa S1 Akuntansi Angkatan 2011 Universitas Negeri Yogyakarta

Hipotesis pertama yaitu Sifat Machiavellian berpengaruh terhadap Dysfunctional Behavior pada Mahasiswa S1 Akuntansi Angkatan 2011 Universitas Negeri Yogyakarta diterima. Hal ini ditunjukkan pada uji 国国国回 diketahui nilainya sebesar 2.093, dimana nilai tersebut lebih besar dari 国国国回 sebesar 1,667.

Adapun persamaan regresinya adalah $\mathrm{Y}_{1}=14,433+0,007 \mathrm{X}_{1}$. Persamaan tersebut menunjukkan bahwa nilai $a$ dan $b$ positif. Artinya ketika variabel $\mathrm{X}_{1}$ (Sifat Machiavellian) dinaikkan maka nilai Y (Dysfunctional Behavior) juga naik mengikuti perubahan variabel $X_{1}$. Nilai signifikansi yang diperoleh 0,000 lebih kecil dari 0,05, yang berarti pengaruhnya signifikan. Hasil tersebut menunjukkan bahwa Sifat Machiavellian berpengaruh terhadap Dysfunctional Behavior pada Mahasiswa S1 Akuntansi Angkatan 2011 Universitas Negeri Yogyakarta.

2. Pengaruh Perkembangan Moral terhadap Dysfunctional Behavior pada Mahasiswa S1 Akuntansi Angkatan 2011 Universitas Negeri Yogyakarta

Hipotesis kedua yaitu Perkembangan Moral berpengaruh terhadap Dysfunctional Behavior pada Mahasiswa S1 Akuntansi Angkatan 2011 Universitas Negeri Yogyakarta diterima. Hal ini ditunjukkan dengan uji 国国国国 diketahui nilainya 2,108, dimana nilai tersebut lebih besar dari 国国国国 $\operatorname{sebesar~1,667.~}$

Adapun persamaan regresi adalah $\mathrm{Y}_{1}=15,096-0,009 \mathrm{X}_{2}$. Persamaan tersebut menunjukkan bahwa nilai $a$ positif dan $b$ negatif. Artinya ketika variabel $\mathrm{X}_{1}$ (Perkembangan Moral) dinaikkan maka nilai Y (Dysfunctional Behavior) juga turun mengikuti perubahan variabel $\mathrm{X}_{2}$. Nilai signifikansi yang diperoleh 0,002 lebih kecil dari 0,05 yang berarti pengaruhnya signifikan. Hasil tersebut menunjukkan bahwa Perkembangan Moral berpengaruh terhadap Dysfunctional Behavior pada Mahasiswa S1 Akuntansi Angkatan 2011 Universitas Negeri Yogyakarta. 


\section{Pengaruh Perkembangan Moral dan Sifat Machiavellian terhadap Dysfunctional Behavior pada Mahasiswa S1 Akuntansi Angkatan 2011 Universitas Negeri Yogyakarta}

Hipotesis ketiga yaitu Perkembangan Moral dan Sifat Machiavellian berpengaruh terhadap Dysfunctional Behavior pada Mahasiswa S1 Akuntansi Angkatan 2011

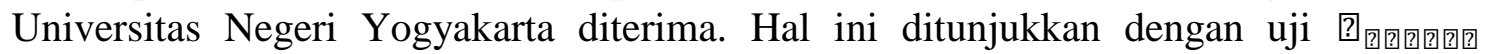
dengan tingkat signifikan 5\% diketahui nilainya 11,010 dimana nilai tersebut lebih besar dari 目国国国 sebesar 3,15 .

Adapun persamaan regresi ganda adalah $\mathrm{Y}=14,845+0,006 \mathrm{X}_{1}-0,008 \mathrm{X}_{2}$. Persamaan tersebut menunjukkan bahwa nilai $a, b_{1}$ positif dan $b_{2}$ negatif, artinya ketika variabel $\mathrm{X}_{1}$ (Sifat Machiavellian) dinaikkan dan variabel $\mathrm{X}_{2}$ (Perkembangan Moral) di turunkan maka nilai Y (Dysfunctional Behavior) juga mengikuti perubahan variabel $\mathrm{X}_{1}$ dan $\mathrm{X}_{2}$. Hasil ini menunjukkan bahwa Sifat Machiavellian dan Perkembangan Moral berpengaruh terhadap Dysfunctional Behavior pada Mahasiswa S1 Akuntansi Angkatan 2011 Universitas Negeri Yogyakarta.

\section{E. Kesimpulan}

Berdasarkan hasil pembahasan di atas, mengenai pengaruh Sifat Machiavellian dan Perkembangan Moral terhadap Dysfunctional Behavior Studi Kasus pada Mahasiswa S1 Akuntansi Angkatan 2011 Universitas Negeri Yogyakarta, maka dapat disimpulkan sebagai berikut :

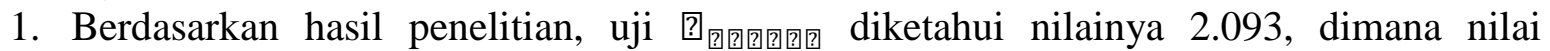
tersebut lebih besar dari 国国国回 sebesar 1,667. Pada persamaan regresi adalah $\mathrm{Y}_{1}=$ $14,433+0,007 \mathrm{X}_{1}$. Persamaan tersebut menunjukkan bahwa nilai $a$ dan $b$ positif, artinya ketika variabel $\mathrm{X}_{1}$ (Sifat Machiavellian) dinaikkan maka nilai Y (Dysfunctional Behavior) juga naik mengikuti perubahan variabel $\mathrm{X}_{1}$. Hasil ini menunjukkan bahwa Sifat Machiavellian berpengaruh terhadap Dysfunctional Behavior pada Mahasiswa S1 Akuntansi Angkatan 2011 Universitas Negeri Yogyakarta.

2. Berdasarkan hasil penelitian, uji 国国国回 diketahui nilainya 2,108 , dimana nilai tersebut lebih besar dari 国国国回 sebesar 1,667. Pada persamaan regresi adalah $\mathrm{Y}_{1}=$ $15,096-0,009 \mathrm{X}_{2}$. Persamaan tersebut menunjukkan bahwa nilai $a$ positif dan $b$ negatif, artinya ketika variabel $\mathrm{X}_{1}$ (Perkembangan Moral) dinaikkan maka nilai $\mathrm{Y}$ (Dysfunctional Behavior) juga turun mengikuti perubahan variabel $\mathrm{X}_{2}$...Hasil ini menunjukkan bahwa Perkembangan Moral berpengaruh terhadap Dysfunctional Behavior pada Mahasiswa S1 Akuntansi Angkatan 2011 Universitas Negeri Yogyakarta.

3. Berdasarkan hasil penelitian, ditunjukkan hasil uji 国国国国 dengan tingkat signifikan 5\% diketahui nilainya 11,010 dimana nilai tersebut lebih besar dari 国国国 sebesar 3,15. Pada persamaan regresi ganda adalah $\mathrm{Y}=14,845+0,006 \mathrm{X}_{1}-0,008 \mathrm{X}_{2}$. Persamaan tersebut menunjukkan bahwa nilai $a, b_{1}$ positif dan $b_{2}$ negatif, artinya ketika variabel $\mathrm{X}_{1}$ (Sifat Machiavellian) dinaikkan dan variabel $\mathrm{X}_{2}$ (Perkembangan Moral) di turunkan maka nilai Y (Dysfunctional Behavior) juga mengikuti perubahan variabel $\mathrm{X}_{1}$ dan $\mathrm{X}_{2}$. Hasil ini menunjukkan bahwa Sifat Machiavellian dan Perkembangan Moral berpengaruh terhadap Dysfunctional Behavior pada Mahasiswa S1 Akuntansi Angkatan 2011 Universitas Negeri Yogyakarta.

\section{DAFTAR PUSTAKA}

Chrismatuti dan Purnamasari. 2004. "Hubungan Sifat Machiavellian, Pembelajaran Etika dalam Mata Kuliah Etika dan Sikap Etis Akuntan”. Lembaga Penelitian Universitas Semarang. 
Gosh dan Crain. 1996. "Experimental Investigation of Ethical Standart and Perceived Probability on International Noncompliance”. Behavior Research in Accounting 8.

Richmond, Kelly A.2001. "Ethical Reasoning, Machivealian Behavior, and Gender, The Impact on Accounting Students' Ethical Decision Making”. Desertasi. Blacksburg. Virginia.

Sukrisno, Agoes. 2009. "Etika Bisnis dan Profesi”. Jakarta : Salemba Empat.

Walker. 2007. "Analisis Pengaruh Intensitas Moral terhadap Intensi Keperilakuan: Peranan Masalah Etika Persepsian dalam Pengambilan Keputusan Etis yang Terkait dengan Sistem Informasi”. 